\title{
Avaliação da resistência adesiva e do padrão de descolagem de diferentes sistemas de colagem de braquetes associados à clorexidina
}

\author{
Jorge Luís de Oliveira Ribeiro*, Rebeca Barroso Bezerra**, Elisângela de Jesus Campos***,

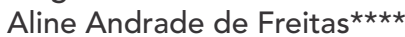

\begin{abstract}
Resumo
Objetivos: o objetivo deste estudo in vitro foi avaliar a resistência adesiva e o padrão de descolagem de diferentes sistemas de colagem de braquetes (Sistema Transbond XT / 3M-Unitek e Sistema Enlight / Ormco) cujos respectivos adesivos foram pré-misturados ao verniz de clorexidina (Cervitec / Ivoclar-Vivadent). Metodologia: a amostra utilizada foi constituída por 60 pré-molares humanos, extraídos por indicações ortodônticas, incluídos em cilindros de PVC e divididos aleatoriamente em quatro grupos: grupo 1 - Sistema Transbond XT conforme prescrito pelo fabricante; grupo 2 - Sistema Transbond XT associado a verniz de clorexidina; grupo 3 - Sistema Enlight conforme prescrito pelo fabricante; grupo 4 - Sistema Enlight associado a verniz de clorexidina. A resistência adesiva foi avaliada pelo teste de cisalhamento na máquina de ensaios universal EMIC $(0,5 \mathrm{~mm} / \mathrm{min})$; o padrão de descolagem foi avaliado, através da lupa estereoscópica STEMI 2000-C / Zeiss (20x), pela observação do Índice de Adesivo Remanescente (IAR) na superfície do esmalte dentário, após a descolagem dos braquetes. Resultados: não houve diferença estatisticamente significante $(\mathrm{p}<0,05)$ entre os grupos experimentais (grupos 2 e 4 ) e os respectivos grupos controles (grupos 1 e 3 ). Conclusões: a resistência adesiva e o padrão de descolagem não foram alterados pela associação do verniz de clorexidina aos respectivos adesivos dos sistemas de colagem testados.
\end{abstract}

Palavras-chave: Braquetes ortodônticos. Resistência ao cisalhamento. Clorexidina.

\section{INTRODUÇÃO}

Apesar da grande evolução ocorrida, nos últimos vinte anos, no sistema de instalação dos aparelhos ortodônticos fixos, em que os braquetes e demais acessórios passaram a ser colados diretamente à superfície do esmalte dentário, persiste uma grande preocupação quanto à manutenção da integridade dos tecidos dentários, sobretudo durante a fase ativa do tratamento, pois a aparatologia ortodôntica fixa continua favorecendo o acúmulo do biofilme dentário e dificultando a higienização bucal. Esses dois fatores associados potencializam o risco de ocorrência de desmineralizações do esmalte dentário e, por conseguinte, instalação da doença cárie, cujas manifestações podem variar desde o aparecimento de lesões de

* Mestre em Odontologia pela Faculdade de Odontologia da UFBA. Especialista em Ortodontia pela ABO-BA.

Mestre e Doutora em Dentística pela Faculdade de Odontologia da USP. Professora do departamento de Odontologia Restauradora da Faculdade de Odontologia da UFBA.

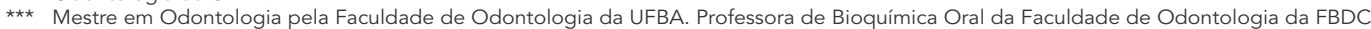

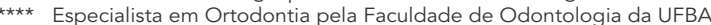


mancha branca na superfície dentária até a formação de lesões cavitadas envolvendo, inclusive, tecidos dentários mais profundos.

Diante desse risco, têm-se buscado alternativas para incorporar ao meio bucal ortodôntico substâncias antimicrobianas que proporcionem controle químico do biofilme dentário, tornando-se uma ferramenta adicional de proteção aos tecidos dentários. Nesse sentido, a clorexidina tem assumido papel de destaque devido à sua capacidade de interferir na aderência bacteriana à película adquirida, além de coagular o citoplasma bacteriano e proporcionar rompimento da sua membrana.

A importância desse tema assume maior relevância na medida em que se busca um direcionamento do controle químico do biofilme dentário às áreas de maior risco, principalmente a superfície do esmalte dentário circunjacente aos braquetes. Por conseguinte, a clorexidina deve estar presente o mais próximo da interface dente-braquete. Assim, o presente estudo se propõe a avaliar a influência da incorporação de clorexidina na resistência adesiva e no padrão de descolagem de diferentes sistemas de colagem de braquetes.

\section{REVISÃO DE LITERATURA}

O conceito de prevenção à cárie dentária abrange, atualmente, todas as áreas da Odontologia. Na Ortodontia, a freqüência de ocorrência de lesões de mancha branca tem preocupado muitos profissionais, haja vista que, reconhecidamente, a aparatologia ortodôntica, por suas características inerentes, favorece a retenção e o acúmulo do biofilme dentário, dificultando o processo de higienização habitual ${ }^{28}$. Segundo Basdra, Huber e Komposch $^{3}$, as desmineralizações têm sido relatadas em mais de $50 \%$ dos dentes tratados com braquetes e em mais de $50 \%$ dos pacientes ortodônticos.

Devido ao maior acúmulo de biofilme, os pacientes portadores de aparelhos ortodônticos devem ser instruídos a manter uma boa higiene bucal, em virtude do maior risco a que estão sujeitos $^{25}$ que corresponde, para os tecidos duros e periodonto, à época da colocação do aparelho fixo e os quatro meses seguintes ${ }^{21}$. Nesse período, aumenta o acúmulo de placa, também naqueles pacientes que exercem uma boa higiene bucal. Conseqüentemente, o ortodontista e a sua equipe têm que dar ênfase ao tratamento preventivoterapêutico ${ }^{13}$.

Quando os princípios de higienização adequada são negligenciados, os danos podem ser consideráveis e os benefícios do tratamento ortodôntico questionáveis ${ }^{28}$, pois a patogenicidade do biofilme dentário aumenta ${ }^{23}$. Nesses casos, Heintze ${ }^{13}$ preconizou a interrupção do tratamento ortodôntico e afirmou que os danos resultantes de um tratamento interrompido são, por muitas vezes, menores do que os danos que se desenvolvem nos tecidos duros ou periodonto devido à deficiência na colaboração do paciente ou da avaliação incorreta do risco de cárie ou de periodontite.

Numa avaliação microscópica das áreas adjacentes às bordas dos braquetes, constatou-se níveis aumentados de Streptococcus mutans e, também, na contagem total de bactérias, desde a primeira semana do tratamento ortodôntico ${ }^{4}$, ou seja, os acessórios ortodônticos colados ainda promovem e favorecem a retenção de placa bacteriana e indultos, aumentando tanto o risco de cárie quanto o de gengivite ${ }^{13,28}$.

Diante dessa constatação, as pesquisas acerca da obtenção do material ideal de colagem direta tomaram novos rumos, pois, além da capacidade retentiva, necessitam demonstrar também propriedades anticariogênicas ${ }^{12}$. Segundo Pascotto ${ }^{19}$ e Simplício ${ }^{26}$, o material adesivo ideal para a Ortodontia deve possuir boa resistência e força de adesão, sem, contudo, danificar o esmalte no momento da descolagem, além de proporcionar ação cariostática.

Várias pesquisas têm demonstrado a utilização da clorexidina no controle das colônias bacterianas, sobretudo dos Streptococcus mutans, em meio bucal, durante tratamentos ortodônticos fixos. Isto se deve ao fato de se tratar de um dos 
agentes antissépticos ou antibacterianos de amplo espectro mais usados na Odontologia, demonstrando ser muito eficiente no controle do biofilme dentário, sem desenvolver organismos resistentes na flora bucal ${ }^{8}$.

A ação bactericida da clorexidina é dirigida principalmente para bactérias Gram positivas, Gram negativas e leveduras, além do seu efeito seletivo sobre Streptococcus mutans. A inibição da formação do biofilme pode ser explicada por dois mecanismos cuja competição da clorexidina com o cálcio prejudica a aderência bacteriana à superfície dentária: (1) a clorexidina se liga aos grupos aniônicos das glicoproteínas salivares, reduzindo a formação da película adquirida e a colonização bacteriana; (2) a clorexidina se adsorve fortemente aos grupos negativos da superfície de bactérias Gram positivas, interferindo na sua ligação aos dentes. Além disso, a clorexidina pode desativar a glicosiltransferase, importante na aderência bacteriana e, também, deslocar cálcio dos grupos sulfatos do biofilme, desintegrando, assim, o biofilme já estabelecido ${ }^{24}$. A sua atividade bactericida, propriamente dita, se dá através da coagulação do citoplasma da bactéria, seguindo-se o rompimento da membrana celular. Essa atividade é dependente do $\mathrm{pH}$, sendo a faixa ótima entre 5,5 e 7 , que corresponde ao $\mathrm{pH}$ das superfícies do corpo e dos tecidos, notadamente na mucosa bucal ${ }^{16}$. Devido à sua forma de atuação, sobretudo através de uma perturbação generalizada da membrana bacteriana, e não sobre receptores ou enzimas bacterianos específicos, a possibilidade de desenvolvimento de resistência bacteriana à clorexidina, mesmo em usos prolongados, é mínima ${ }^{24}$.

Vários autores têm procurado incorporar os benefícios advindos da utilização da clorexidina ao meio bucal ortodôntico, sob as mais diversas formas de administração. Madléna et al. ${ }^{15}$ avaliaram o efeito antibacteriano de um verniz contendo clorexidina (Cervitec - Ivoclar/Vivadent, Ontário, Canadá), aplicado trimestralmente, durante o tratamento ortodôntico. Seus resultados demonstraram que o verniz contendo clorexidina reduziu eficientemente o número de Streptococcus mutans ao redor dos acessórios ortodônticos fixos. Além disso, percebeu-se que o número de novas lesões cariosas, após a descolagem dos aparelhos ortodônticos fixos, foi significantemente menor nos quadrantes que receberam aplicações do verniz Cervitec, quando comparados aos demais quadrantes.

Beyth et al. ${ }^{4}$ realizaram um estudo onde avaliaram o efeito do verniz de clorexidina em pacientes ortodônticos, através da contagem de Streptococcus mutans. Por conseguinte, evidenciaram uma redução nos níveis bacterianos, após utilização do verniz de clorexidina, em pacientes ortodônticos com aparelhos fixos e, portanto, sugeriram a utilização desse verniz como medida útil na prevenção de lesões cariosas.

Alguns trabalhos buscam incorporar a clorexidina ao sistema adesivo utilizado na colagem direta de braquetes, a fim de adicionar os seus benefícios anticariogênicos, de uma forma mais direcionada às regiões imediatamente adjacentes e/ou sob os braquetes, avaliando, em contrapartida, eventuais interferências na capacidade adesiva do sistema. Damon et al. ${ }^{8}$, em 1997, incorporaram verniz de clorexidina (Cervitec) ao adesivo do sistema de colagem Transbond XT (3M/Unitek, Califórnia, EUA), numa proporção de 2:1, respectivamente, e avaliaram a resistência de colagem ao cisalhamento e os tipos de falha braquete/adesivo/dente. Ao final do estudo, concluíram que o adesivo contendo clorexidina não afetou significantemente a resistência da colagem ao cisalhamento, nem o local da falha de colagem. Portanto, o uso da mistura clorexidina-adesivo poderia ser recomendado como parte do protocolo de colagem direta de braquetes.

Em 1998, Bishara et al. ${ }^{5}$ realizaram um estudo visando avaliar a resistência da colagem ao cisalhamento e a falha braquete/adesivo/dente em diferentes formas de utilização de clorexidina: (1) verniz sobre os braquetes e superfícies dentárias após 
o procedimento de colagem; (2) pasta profilática contendo clorexidina $0,12 \%$, sobre o esmalte intacto, antes do condicionamento ácido; (3) verniz misturado ao adesivo Transbond XT e aplicado ao esmalte condicionado antes da colagem; (4) verniz aplicado ao esmalte condicionado sem selante; (5) verniz sobre o selante fotopolimerizado; (6) verniz sobre o selante antes de ser fotopolimerizado. Os resultados desse estudo indicaram que a resistência da colagem ao cisalhamento não foi afetada significativamente com a aplicação da clorexidina nas três primeiras formas de utilização, ou seja, como verniz sobre os braquetes, como pasta profilática e quando o verniz foi pré-misturado ao adesivo e aplicado sobre a superfície do esmalte condicionado. Nas demais formas, sobretudo quando foi aplicada sobre a superfície do esmalte condicionado ou sobre o adesivo, os valores de resistência da colagem ao cisalhamento e os índices de falha braquete/adesivo obtiveram uma magnitude que os tornou clinicamente inaceitáveis.

\section{PROPOSIÇÃO}

O presente estudo se propôs a avaliar, in vitro, a influência da incorporação de clorexidina na resistência adesiva e no padrão de descolagem de diferentes sistemas de colagem de braquetes, através de ensaios mecânicos de cisalhamento e observação do adesivo remanescente à superfície dentária após a descolagem de braquetes.

\section{MATERIAL E MÉTODOS}

Foram utilizados 60 pré-molares humanos, com faces vestibulares hígidas, recém-extraídos por indicações ortodônticas. Após exodontias, os dentes foram limpos, polidos com escovas de Robinson, lavados em água corrente e armazenados em soro fisiológico, numa estufa a $37^{\circ} \mathrm{C}$, cuja solução foi renovada semanalmente.

Esses dentes foram incluídos em cilindros de PVC $(3 \mathrm{~cm}$ de altura $\mathrm{x} 4 \mathrm{~cm}$ de diâmetro), preenchidos por resina ortofitálica cristal. No momento da inclusão, utilizou-se um esquadro justaposto ao centro das faces vestibulares, de forma que essas faces ficassem perpendiculares ao solo. Em seguida, realizou-se profilaxia nas coroas dentárias, em baixa rotação, com taça de borracha, pedra-pomes e água. Após secagem com ar isento de umidade e óleo, delimitou-se a área de colagem dos braquetes (centro da face vestibular) com fita adesiva Silver Tape (3M, Sumaré/SP) no formato circular, com $7 \mathrm{~mm}$ de diâmetro, cuja porção central havia sido perfurada (vazada) em forma de círculo de $4 \mathrm{~mm}$ de diâmetro. Essa delimitação teve a finalidade de impedir extravasamento do material de colagem para áreas distantes. A partir daí, a amostra foi numerada e dividida, aleatoriamente, em 4 grupos, cada grupo com 15 dentes, iniciando-se a colagem dos braquetes.

Em cada dente, no local delimitado pela fita adesiva, colou-se um braquete Edgewise da marca Morelli (código: 10.65.106). Para isso, foram utilizados sistemas de colagem de resinas compostas fotopolimerizáveis e fotopolimerizador de luz halógena Optilight Plus (Gnatus, Ribeirão Preto/ SP) com intensidade de luz aferida em torno de $500 \mathrm{~mW} / \mathrm{cm}^{2}$.

O procedimento de colagem consistiu, inicialmente, no condicionamento ácido do centro da face vestibular com ácido fosfórico a 35\% (3M ESPE, Minnesota, EUA), durante 15 segundos. Em seguida, procedeu-se a lavagem com água, por 30 segundos, seguida de secagem com ar isento de umidade e óleo. Posteriormente, realizou-se a colagem dos braquetes propriamente dita, de acordo com o protocolo do grupo ao qual pertencia cada dente, conforme abaixo descrito:

- Grupo 1 (controle) - Sistema Transbond XT (3M/Unitek): adesivo Transbond XT aplicado, com auxílio de um pincel, na superfície do esmalte condicionado; em seguida, aplicação da resina Transbond XT diretamente na base do braquete que, por sua vez, foi pressionado contra a região delimitada na face vestibular do dente; os excessos foram removidos com auxílio de uma sonda exploradora e, em seguida, a resina fotopolimerizada 
por 20 segundos (10 segundos no sentido mesiodistal e 10 segundos no sentido distomesial).

- Grupo 2 - Sistema Transbond XT (3M/Unitek) + verniz Cervitec (Ivoclar/Vivadent): verniz Cervitec foi pré-misturado ao adesivo Transbond XT, na proporção 2:1, e aplicado, com auxílio de um pincel, na superfície do esmalte condicionado; em seguida, efetuou-se a colagem do braquete de forma idêntica ao grupo 1 .

- Grupo 3 (controle) - Sistema Enlight (Ormco, Califórnia, EUA): adesivo Ortho Solo (Ormco) aplicado, com auxílio de um pincel, na superfície do esmalte condicionado; em seguida, aplicação da resina Enlight diretamente na base do braquete que, por sua vez, foi pressionado contra a região delimitada na face vestibular do dente; os excessos foram removidos com auxílio de uma sonda exploradora e, em seguida, a resina fotopolimerizada por 40 segundos (20 segundos no sentido mesiodistal e 20 segundos no sentido distomesial).

- Grupo 4 - Sistema Enlight (Ormco) + verniz Cervitec (Ivoclar/Vivadent): o verniz Cervitec foi pré-misturado ao adesivo Ortho Solo (Ormco), na proporção 2:1, e aplicado, com auxílio de um

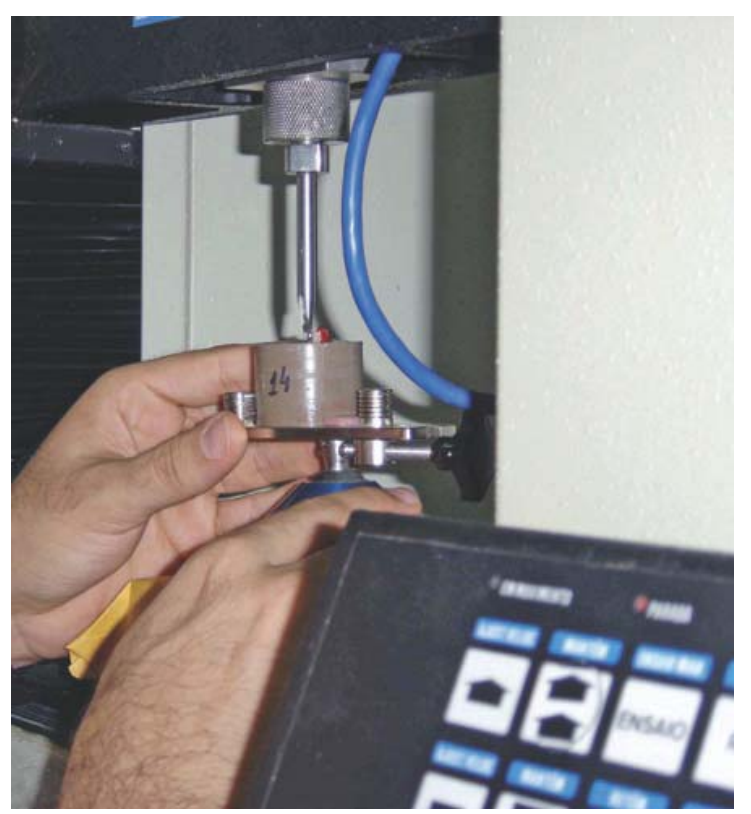

FIGURA 1 - Posicionamento do corpo-de-prova na máquina de ensaios EMIC. pincel, na superfície do esmalte condicionado; em seguida, efetuou-se a colagem do braquete de forma idêntica ao grupo 3 .

Finalizada a colagem dos braquetes, retirouse a fita adesiva e acondicionou-se os corpos-deprova (cilindro de PVC + dente + braquetes) em coletores universais contendo água deionizada, de forma que as coroas dentárias permanecessem hidratadas.

No dia seguinte, os corpos-de-prova foram submetidos ao teste de cisalhamento, na máquina de ensaios universal EMIC (Universidade Estadual de Feira de Santana/BA), conforme figura 1. Para isso, foi confeccionada uma ponta ativa, em forma de cinzel, que se adaptava, o mais perfeito possivel, à base dos braquetes (Fig. 2) e, assim, garantia-se paralelismo da força empregada em relação ao longo eixo da coroa dentária, bem como, padronização da superfície de contato com os braquetes, quando da aplicação da força, cuja ponta ativa deslocavase, pressionando o braquete, a uma velocidade de $0,5 \mathrm{~mm} / \mathrm{min}$. até que ocorresse a ruptura da união braquete-dente. Nesse momento, um programa específico de computador, acoplado à máquina de

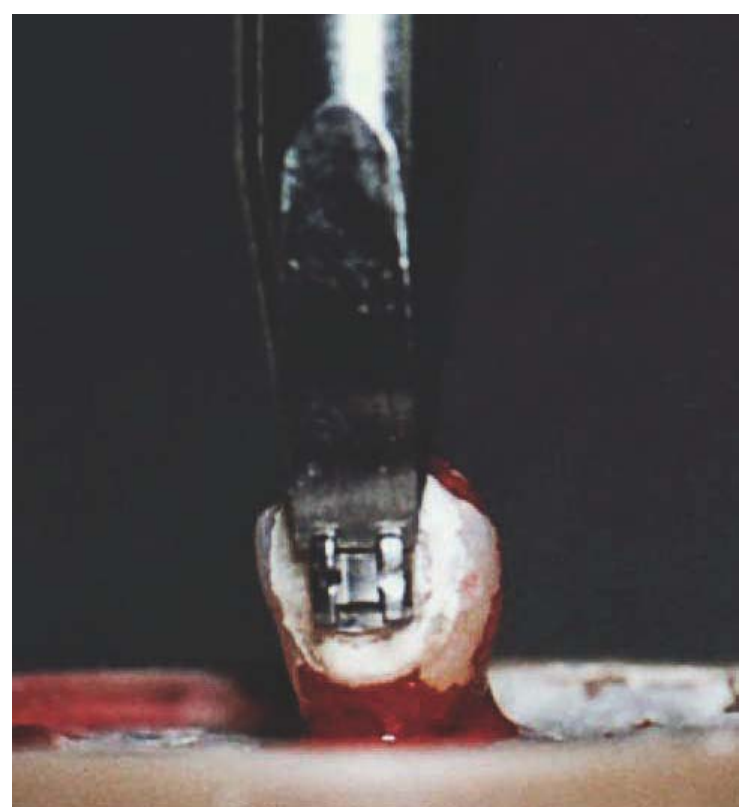

FIGURA 2 - Adaptação da base do braquete à ponta ativa da máquina de ensaios. 
ensaios, registrava, em Megapascal (MPa), a força necessária para promover ruptura da colagem. Os resultados foram submetidos à avaliação estatística descritiva, análise de variância (ANOVA) e ao teste paramétrico de Tukey, com nível de significância de $95 \%(\mathrm{p}<0,05)$.

Finalizado o teste de resistência ao cisalhamento, os corpos-de-prova foram conservados em água deionizada e, posteriormente, avaliou-se visualmente, através de lupa estereoscópica, STEMI 2000-C (Zeiss, Germany), aumento de 20x, por três examinadores, devidamente calibrados, com mensuração dos erros intra e interexaminadores, as áreas de descolagem - visando constatar a quantidade do remanescente de resina na superfície dentária e, portanto, definir o padrão de fratura do sistema de colagem de cada grupo experimental (ocorrência de falhas adesivas, coesivas ou mistas).

Utilizou-se o Índice de Adesivo Remanescente (IAR), desenvolvido por Artun e Bergland ${ }^{1}$, cujos escores preconizados foram: $0=$ nenhum remanescente de adesivo sobre o dente; $1=$ menos de $50 \%$ de adesivo remanescente no dente; 2 = mais de $50 \%$ de adesivo remanescente no dente; $3=$ todo o adesivo permaneceu sobre o dente. Os resultados foram submetidos ao teste estatístico paramétrico Qui-quadrado de Pearson, com nível de significância de $95 \%(\mathrm{p}<0,05)$.

\section{RESULTADOS}

As forças necessárias para romper a união braquete-dente, em Megapascal, constam do quadro 1.

Através da análise descritiva (Quadro 1) observou-se que os grupos que utilizaram o sistema de colagem Enlight (G3 e G4) apresentaram médias de resistência ao cisalhamento maiores do que os grupos que utilizaram o sistema de colagem Transbond XT (G1 e G2).

Os valores de resistência ao cisalhamento obtidos foram submetidos à análise de variância (ANOVA), com $p<0,05$, constatando-se, por- tanto, a existência de diferenças estatísticas significantes entre os grupos. Visando comparar os diversos grupos entre si, empregou-se o teste de Tukey, com intervalos de confiança a $95 \%$, cujos resultados estão descritos no gráfico 1 . Através da dispersão dos seus dados, confirmou-se a maior resistência dos grupos que utilizaram o sistema de colagem Enlight, entretanto, apenas o grupo 3 diferiu, de forma estatisticamente significante, dos grupos 1 e 2 (Gráf. 1).

Comparando-se a resistência ao cisalhamento dos grupos experimentais aos seus respectivos grupos controles, constatou-se que o grupo 2 (Transbond XT + Cervitec) não apresentou diferença estatisticamente significante em relação ao grupo 1 (grupo controle para o sistema Transbond XT), bem como o grupo 4 (Enlight + Cervitec) não apresentou diferença estatisticamente significante em relação ao grupo 3 (grupo controle para o sistema Enlight), conforme intervalos de confiança demonstrados no gráfico 1 .

Para avaliação do padrão de descolagem dos

\begin{tabular}{ccccc}
\hline dente & grupo $\mathbf{1}$ & grupo 2 & grupo 3 & grupo 4 \\
\hline $\mathbf{1}$ & 4,57 & 3,87 & 9,67 & 5,11 \\
$\mathbf{2}$ & 4,88 & 5,96 & 11,15 & 8,67 \\
$\mathbf{3}$ & 6,04 & 6,73 & 12,38 & 8,90 \\
$\mathbf{4}$ & 7,28 & 7,51 & 13,00 & 9,45 \\
$\mathbf{5}$ & 7,28 & 7,82 & 13,00 & 10,30 \\
$\mathbf{6}$ & 7,66 & 8,98 & 13,47 & 12,39 \\
$\mathbf{7}$ & 8,67 & 9,06 & 14,32 & 12,62 \\
$\mathbf{8}$ & 9,21 & 9,60 & 14,63 & 13,63 \\
$\mathbf{9}$ & 9,21 & 9,91 & 15,71 & 14,63 \\
$\mathbf{1 0}$ & 9,60 & 10,37 & 16,49 & 14,94 \\
$\mathbf{1 1}$ & 10,37 & 10,91 & 17,26 & 14,94 \\
$\mathbf{1 2}$ & 10,99 & 11,77 & 17,34 & 15,48 \\
$\mathbf{1 3}$ & 13,24 & 12,31 & 17,57 & 16,41 \\
$\mathbf{1 4}$ & 14,48 & 15,33 & 18,19 & 18,12 \\
$\mathbf{1 5}$ & 20,67 & 15,64 & 9,67 & 20,13 \\
$\mathbf{m e ́}$ & 9,61 & 9,71 & 14,92 & 13,05 \\
\hline & & & & \\
\hline
\end{tabular}

Quadro 1 - Resistência ao cisalhamento, em Megapascal, dos corpos-de-prova individualmente e média apresentada por cada grupo do estudo. 


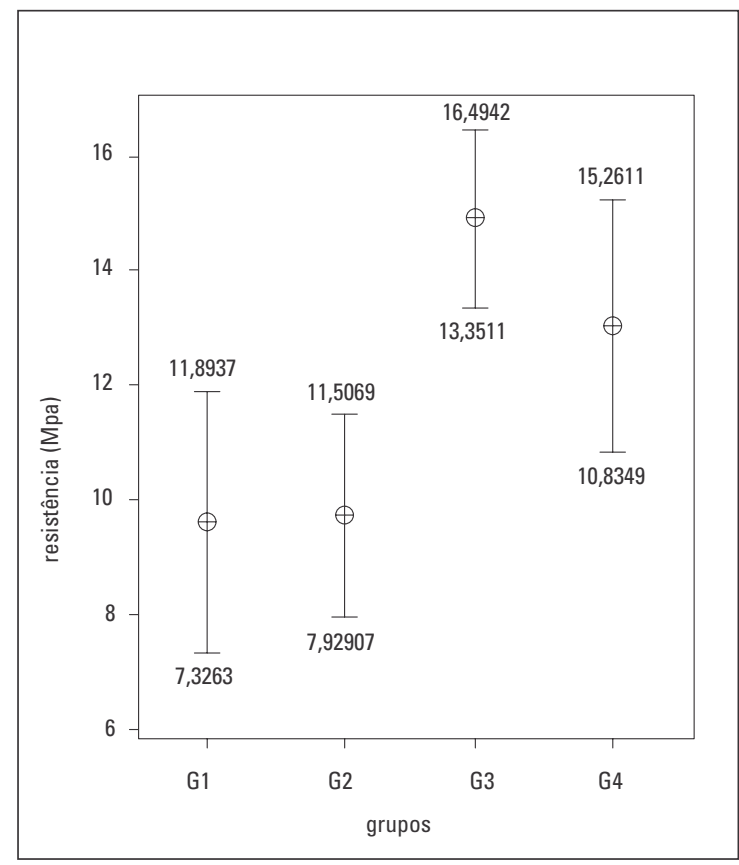

GRÁFICO 1 - Médias e intervalos de confiança (95\%) da resistência ao cisaIhamento (Mpa) de cada grupo.

braquetes, aplicou-se o índice IAR (Índice de Adesivo Remanescente) cujas leituras foram realizadas através de lupa estereoscópica, por 3 examinadores devidamente calibrados (CKappa $=$ $0,886726)$. Os resultados estão descritos no gráfico 2, com predominância do escore 3 (todo o adesivo permaneceu sobre o dente) para os grupos que utilizaram o sistema de colagem Transbond XT e predominância do escore 2 (mais de 50\% de adesivo remanescente no dente) para os grupos que utilizaram o sistema de colagem Enlight.

\section{DISCUSSÃO}

Os aparelhos ortodônticos, conforme afirmação unânime dos autores pesquisados ${ }^{13,23,25,28}$, favorecem a retenção e o acúmulo do biofilme dentário, principalmente, por baixo das bandas ortodônticas e ao redor da base dos braquetes, com destaque para as regiões do esmalte dentário relacionadas ao lado cervical dos braquetes. Além disso, a presença desses componentes ortodônticos

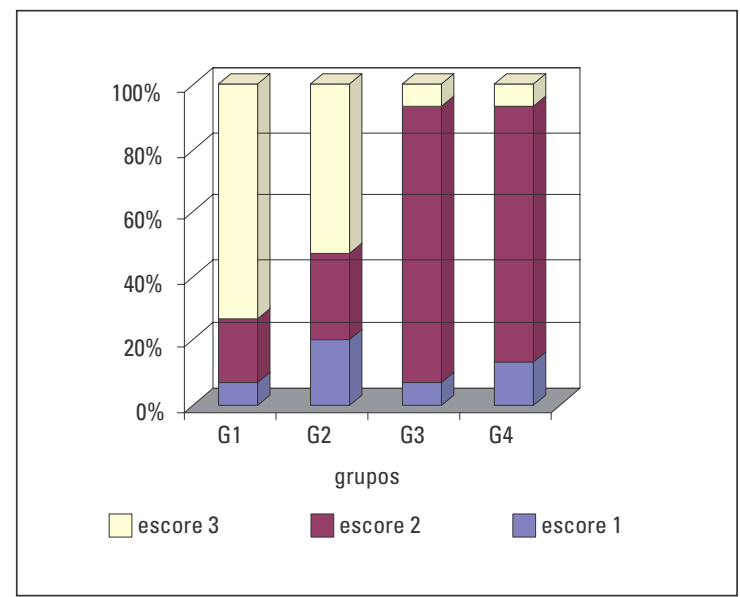

GRÁFICO 2 - Padrão de descolagem dos grupos experimentais, através do Índice de Adesivo Remanescente (IAR).

associados aos seus respectivos acessórios (tubos, ganchos, elásticos, arcos e aletas) dificulta a higienização bucal adequada pelo paciente, potencializando o risco de ocorrência de desmineralização do esmalte dentário e, por conseguinte, instalação de lesões cariosas.

Diante dessa realidade, em que o tratamento ortodôntico faz-se necessário e, inevitavelmente, sua aparatologia proporciona um aumento na retenção e acúmulo de biofilme dentário, cuja higienização depende muito da participação e colaboração dos pacientes, objetiva-se encontrar novas alternativas, inclusive químicas, que auxiliem na proteção da superfície dentária e/ou no controle do biofilme dentário, visando reduzir os riscos das doenças dentárias que tanto afetam a saúde bucal $2,4,5,8,15$. Dentre as substâncias químicas mais utilizadas, assume papel de destaque a clorexidina, considerada um dos agentes antibacterianos mais usados na Odontologia ${ }^{8}$, capaz de desempenhar uma ação bactericida importantíssima no controle das colônias bacterianas, sobretudo dos Streptococcus mutans, proporcionando, seguramente, benefícios anticariogênicos.

$\mathrm{Na}$ tentativa de incorporar clorexidina aos sistemas de colagem de braquetes, faz-se necessária a avaliação da resistência adesiva dos sistemas tes- 
tados, pois os possíveis benefícios advindos dessa incorporação não poderão significar prejuízo na resistência adesiva da interface dente-braquete, sobretudo a níveis abaixo daqueles considerados clinicamente aceitáveis que, segundo Reynolds ${ }^{22}$ corresponderiam a, no mínimo, uma resistência de 6 a 8 Megapascais (MPa). Estes dados estão em acordo com os de Osório et al. ${ }^{18}$

$\mathrm{Na}$ avaliação da resistência adesiva do presente estudo, optou-se pelo teste de cisalhamento devido ao sentido das forças aplicadas clinicamente nos braquetes ortodônticos ser predominantemente de cisalhamento ${ }^{9}$ e, por conseguinte, à similaridade desse ensaio com as forças que, clinicamente, mais resultam em falhas na adesão de braquetes $^{6,10,11,17,20,27}$. Além disso, segundo $\mathrm{Cal}$ Neto e Miguel $^{7}$, nos anos de 1993 a 2002, o ensaio de cisalhamento foi utilizado em $84 \%$ dos estudos que testaram a resistência da força de adesão de sistemas de colagem de braquetes.

Observando-se os resultados obtidos nos grupos que utilizaram o sistema Transbond XT, percebeu-se que a associação do verniz Cervitec ao adesivo, na proporção 2:1, não afetou a resistência da colagem, conforme achados de Damon et al. ${ }^{8}$ e Bishara et $a 1 .^{5}$ Esses achados, também podem ser projetados para a associação do sistema de colagem Enlight com a clorexidina, pois o verniz Cervitec pré-misturado ao adesivo Ortho Solo, na proporção 2:1, também não interferiu na resistência adesiva do sistema de colagem. Portanto, a associação do verniz Cervitec ao sistema de colagem foi satisfatória, quanto à resistência adesiva, tanto para adesivos hidrofóbicos (Transbond XT) quanto para adesivos hidrofilicos (Ortho Solo).

A colagem ortodôntica pressupõe a firme união entre o esmalte dentário e a base de um acessório ortodôntico, tendo como agente de união o adesivo. Portanto, as descolagens podem ocorrer devido a fraturas adesivas nas interfaces esmalte/adesivo ou acessório/adesivo; fraturas coesivas ocorridas no esmalte, no material adesivo ou no acessório; ou ainda uma combinação de fraturas adesivas e $\operatorname{coesivas}^{14}$. Não existe um consenso na literatura científica de qual seria a forma ideal do padrão de descolagem dos braquetes, entretanto parece lógico afirmar que a prioridade é que a descolagem não proporcione quaisquer danos à superfície do esmalte dentário.

Analisando os grupos que utilizaram o sistema Transbond XT (com ou sem verniz Cervitec), houve predominância do escore 3 do IAR (Gráf. 2) e, portanto, de fraturas adesivas na interface adesivo/braquete. Por conseguinte, pôde-se afirmar que a associação do verniz Cervitec ao adesivo Transbond XT, na proporção 2:1, não alterou o padrão predominante de descolagem, quando comparado ao seu respectivo grupo controle. Vale ressaltar, ainda, que nesses grupos, a possibilidade de fraturas de esmalte associadas às descolagens de braquetes está bastante reduzida, pois os remanescentes do adesivo permaneceram, em sua grande maioria, sobre a superfície dentária. Além disso, não houve ocorrência do padrão de descolagem escore 0 (nenhum remanescente de adesivo sobre o dente), portanto, ausência de falhas adesivas na interface dente/adesivo, assegurando uma boa adesão do sistema Transbond XT à superfície dentária.

Já os grupos que utilizaram o sistema de colagem Enlight (com ou sem verniz Cervitec) demonstraram predominância do escore 2 do IAR (Gráf. 2) e, portanto, uma combinação de fraturas adesivas e coesivas. Apesar de demonstrarem padrão de descolagem predominante distinto do sistema Transbond XT, pôde-se afirmar, também, que associação do verniz Cervitec ao adesivo Ortho Solo, na proporção 2:1, não alterou o padrão predominante de descolagem, quando comparado ao seu respectivo grupo controle. Nesses grupos, a possibilidade de fraturas de esmalte associadas às descolagens de braquetes é um pouco maior, quando comparada ao sistema Transbond XT, haja vista que parte da superfície do esmalte dentário apresentou-se isenta de adesivo remanescente e, portanto, exposta a maiores índices de fraturas 
coesivas no esmalte que, por sua vez, apresentam uma correlação direta com a perda de sua integridade no momento das descolagens.

Portanto, diante desses resultados, ratificase a possibilidade de incorporar, ao protocolo de colagem de braquetes, a utilização do verniz de clorexidina Cervitec, pré-misturado ao adesivo, na proporção 2:1, na tentativa de propiciar o controle químico do biofilme dentário, auxiliando na proteção da unidade dentária frente aos riscos cariogênicos durante o tratamento ortodôntico com aparelhos fixos, sem prejuizo da resistência adesiva dos sistemas de colagem, tão importante para a resistência às forças ortodônticas e/ou mastigatórias e, também, sem interferir no seu padrão predominante de descolagem.

\section{CONCLUSÃO}

A incorporação de clorexidina aos sistemas de colagem testados, através do verniz Cervitec (Ivoclar/Vivadent), pré-misturado ao adesivo, na pro- porção 2:1, não influenciou na resistência adesiva ao cisalhamento nem no padrão de descolagem dos braquetes.

\section{AGRADECIMENTOS}

À FAPESB, pela concessão de bolsa para a realização da pesquisa.

À 3M/Unitek, pela concessão de parte dos materiais necessários para a realização da pesquisa.

Ao Prof. Dr. Paulo Vicente Rocha (UEFS), pela viabilização do teste de cisalhamento.

\title{
Evaluation of the bond strength and debonding pattern of different bracket bonding systems associated with chlorhexidine
}

\begin{abstract}
Aim: The objective of this in vitro study was to evaluate the bond strength and the debonding pattern of different bracket bonding systems (Transbond XT System / 3M-Unitek and Enlight System / Ormco) whose respective adhesives were pre-mixed with chlorhexidine varnish (Cervitec / Ivoclar-Vivadent). Methods: The sample used consisted of sixty human pre-molars extracted for orthodontic purposes, included in PVC cylinder and randomly divided in four experimental groups: group 1 - Transbond XT System according to the manufacturer's instructions; group 2 - Transbond XT System combined with chlorhexidine varnish; group 3 - Enlight System according to the manufacturer's instructions; group 4 - Enlight System combined with chlorhexidine varnish. The bond strength evaluation was obtained through the shear bond strength test by EMIC universal test machine $(0.5 \mathrm{~mm} / \mathrm{minute})$; the debonding pattern evaluation was obtained by STEMI 2000-C/Zeiss (20x) stereoscopic microscope through observation of the adhesive remnant index (ARI) on the tooth's enamel surface after bracket debonding. Results: Between the experimental groups (groups 2 and 4 ) and the respective control groups (groups 1 and 3 ) there was no significant statistical difference $(p<0.05)$. Conclusions: The bond strength and the debonding pattern were not altered for association of the chlorhexidine varnish with respective adhesives of the tested bonding systems.
\end{abstract}

Key words: Orthodontic brackets. Shear bond strength. Chlorhexidine. 


\section{REFERÊNCIAS}

1. ARTUN, J.; BERGLAND, S. Clinical trials with crystal growth conditioning as an alternative to acid-etch enamel pretreatment. Am. J. Orthod. Dentofacial Orthop., St. Louis, v. 85, no. 4, p. 333-340, Apr. 1984.

2. ATTIN, R. et al. Recolonization of mutans streptococci on teeth with orthodontic appliances after antimicrobial therapy. Eur. J. Orthod., Oxford, v. 27, no. 5, p. 489-493, Oct. 2005.

3. BASDRA, E. K.; HUBER, H.; KOMPOSCH, G. Fluoride release from orthodontic bonding agents alters enamel surface and inhibits enamel desmineralization in vitro. Am. J. Orthod. Dentofacial Orthop. St. Louis, v. 109, no. 5, p. 466-472, May 1996.

4. BEYTH, N. et al. Effect of sustained-release chlorhexidine varnish on Streptococcus mutans and Actinomyces viscosus in orthodontic patients. Am. J. Orthod. Dentofacial Orthop. St. Louis, v. 123, no. 3, p. 345-348, Mar. 2003

5. BISHARA, S. E. et al. Effects of various methods of chlorhexidine application on shear bond strength. Am. J. Orthod. Dentofacial Orthop., St. Louis, v. 114, no. 2, p. 150-153, Aug. 1998.

6. BISHARA, S. E. et al. Effect of a self-etch primer/adhesive on the shear bond strength of orthodontic brackets. Am. J. Orthod. Dentofacial Orthop., St. Louis, v. 119, no. 6, p. 621-624, June 2001

7. CAL NETO J. O. A. P. MIGUEL, J.A. M. Uma análise dos testes in vitro de força de adesão em Ortodontia. Rev. Dental Press Ortodon. Ortop. Facial, Maringá, v. 9, n. 4, p. 44-51, jul./ago. 2004

8. DAMON, P. L. et al. Bond strength following the application of chlorhexidine on etched enamel. Angle Orthod., Appleton, v. 67, no. 3, p. 169-172, 1997.

9. DOLCl, G. S. et al. Resistência de união entre braquetes metálicos e esmalte: avaliação de diferentes materiais. Ortodon. Gaúcha, Porto Alegre, v. 4, n. 2, p. 144-156, jul./dez. 2000.

10. FOX, N. A.; McCABE, J. F.; BUCKLEY, J. G. A critique of bond strength testing in Orthodontics. Br. J. Orthod., Oxford, v. 21, no. 1, p. 33-43, Feb. 1994.

11. FOX, N. A.; McCABE, J. F.; GORDON, P. H. Bond strengths of orthodontic bonding materials: an in vitro study. $\mathbf{B r}$. J. Orthod., Oxford, v. 18, n. 2, p. 125-130, May 1991.

12. HABITOVIC-KOFMAN, $\mathrm{S}$, et al. Glass ionomer as a rechargeable fluoride system. J. Dent. Res., Alexandria, v. 73, p. 134 1994

13. HEINTZE, S. D. A profilaxia individual em pacientes com aparelhos fixos: recomendações para o consultório. Ortodontia, Bauru, v. 29, n. 2, p. 4-15, maio/ago. 1996

14. KAWAKAMI, R. Y. et al. Avaliação in vitro do padrão de descolagem na interface de fixação de materiais adesivos ortodônticos ao esmalte de dentes inclusos: resistência ao cisalhamento após 48 horas e 10 dias. Rev. Dental Press Ortodon. Ortop. Facial, Maringá, v. 8, p. 43-61, nov./dez. 2003.
15. MADLÉNA, M. et al. Effect of chlorhexidine varnish on bacterial levels in plaque and saliva during orthodontic treatment. J. Clin. Dent., Yardley, v. 11, no. 2, p. 42-46, 2000.

16. MELO, G. B. et al. Potencial de eficácia da associação de clorexidina com flúor. Rev. CROMG, Belo Horizonte, v. 5, n. 1, p. 43-46, jan./abr. 1999.

17. MILLET, D. T.; MCCABE, J. F. Orthodontic bonding with glass ionomer cement: a review. Eur. J. Orthod., Oxford, v. 18, no. 4, p. 385-399, 1996.

18. OSÓRIO, R. et al. Bracket bonding with 15 or 60 seconds etching and adhesive remaining on enamel after debonding. Angle Orthod., Appleton, v. 69, no. 1, p. 45-48, Feb. 1999.

19. PASCOTTO, R. C. Avaliação das propriedades anticariogênicas do cimento de ionômero de vidro utilizado na fixação de braquetes ortodônticos: estudo in vivo. 1999 Tese (Doutorado em Dentística)-Faculdade de Odontologia da Universidade de São Paulo, Bauru, 1999.

20. PERDIGÃO, J. et al. Effects of self-etching primer on enamel shear bond strengths and SEM morphology. Am. J. Dent., San Antonio, v. 10, no. 3, p. 141-146, June 1997.

21. PETERSSON, L. G. et al. Mutans streptococci in saliva e interdental spaces after topical applications of an antimicrobial varnish in school-children. Oral Microbiol. Immunol., Copenhagen, v. 6, p. 284-287, 1991

22. REYNOLDS, I. R. A review of direct orthodontic bonding. Br. J. Orthod., Oxford, v. 2, p. 171-178, 1975.

23. REZENDE, C. L. R. D. et al. Influência da aparatologia ortodôntica na colonização microbiana das superfícies dentárias. Rev. Dental Press Ortodon. Ortop. Facial, Maringá, v. 8, n. 2, p. 71-78, mar./abr. 2001.

24. ROSA, O. P. S.; ROCHA, R. S. S. Clorexidina e cárie dentária. Cecade News, Bauru, v. 1, n. 1/2, p. 1-24, jan./ago. 1993.

25. SILVA FILHO, O. G. et al. Placa bacteriana: Ortodontia. Rev. Assoc. Paul. Cir. Dent., São Paulo, v. 43, n. 3, p. 128-132, maio/jun. 1989

26. SIMPLÍCIO, A. H. M. Avaliação in vitro de materiais utilizados para colagem ortodôntica. Potencial cariostático, resistência ao cisalhamento e padrão de descolagem. 2000 Tese (Doutorado em Ortodontia)-Faculdade de Odontologia da Universidade Estadual Paulista, Araraquara, 2000.

27. TALBOT, T. Q. et al. Effect of argon laser irradiation on shear bond strength of orthodontic brackets: an in vitro study. Am. J. Orthod. Dentofacial Orthop., St. Louis, v. 118, no. 3, p. 274-279, Sept. 2000.

28. TAMBURUS, V. S.; BAGATIN, C. R.; SILVA NETO, C. R. Higiene bucal no tratamento ortodôntico: importância da motivação. Rev. Faculd. Odontol. Lins, Lins, v. 11, n. 1, p. 51-57, jan./jun. 1998
Endereço para correspondência

Jorge Luís de Oliveira Ribeiro

Av. Princesa Leopoldina, 596-1201 - Graça

CEP: 40.150-080 - Salvador/BA

E-mail: jloribeiro@oi.com.b 